\title{
INFLUÊNCIA DE DOSAGENS DE CALCÁRIO EM UM LATOSSOLO VERMELHO-AMARELO DISTRÓFICO NO SUL DO TOCANTINS, BRASIL
}

\author{
Olavo Costa Leite ${ }^{1}$, Márcio Silva Melo ${ }^{1}$, Lawrence Nóbrega de Oliveira ${ }^{2}$, Maurício \\ Rodrigues da Costa Sobrinho ${ }^{3}$, Bruno Silva Melo ${ }^{1}$. \\ ${ }^{1}$ Acadêmico do doutorado em Produção Vegetal da Universidade Federal do \\ Tocantins, campus Gurupi, Gurupi, TO - Brasil (marciosilvagemeo@gmail.com) \\ ${ }^{2}$ Mestre em Ciências Florestais e Ambientais pela Universidade Federal do \\ Tocantins, campus Gurupi, Gurupi, TO - Brasil \\ ${ }^{3}$ Graduado em Engenharia Florestal pela a Universidade Federal do Tocantins, \\ campus Gurupi, Gurupi, TO - Brasil IBAMA
}

Recebido em: 22/09/2018 - Aprovado em: 23/11/2018 - Publicado em: 03/12/2018 DOI: 10.18677/EnciBio_2018B55

\begin{abstract}
A maioria dos solos brasileiros, de maneira especial aqueles em que estão ocorrendo a expansão da agricultura, como os solos em regiões de Cerrados, apresentam características de acidez, toxidez de $\mathrm{Al}$ e baixos níveis de $\mathrm{Ca}$ e $\mathrm{Mg}$. Em especial, os solos sob Cerrado Tocantinense, têm indicado problemas em relação com a baixa fertilidade, exigindo aplicações de calcário e fertilizantes para utilização agrícola. Os mesmos apresentam índices de $\mathrm{pH}$ menores que 5,5 com alta concentração de $\mathrm{Al}$ e $\mathrm{Fe}$, e com deficiência nos teores de $\mathrm{P}, \mathrm{K}, \mathrm{Ca}$ e $\mathrm{Mg}$. Assim, objetivou-se estudar a relação dos efeitos da calagem na fertilidade do solo em diferente dosagem, na correção do pH e no nível de toxidez de Al. O experimento foi conduzido em um Latossolo Vermelho-Amarelo Distrófico, na Universidade Federal do Tocantins, campus de Gurupi. As doses empregadas de Carbonato de Cálcio PA foram: 0,$0 ; 1,5 ; 3,0 ; 4,5$ e 6,0 ton ha ${ }^{-1}$. A cada 10 dias foram realizadas avaliações em laboratório do nível do pH em água. Verificou-se que aplicação do carbonato de Cálcio favoreceu a elevação do $\mathrm{pH}$, diminuindo os teores de $\mathrm{Al}$ e $\mathrm{Fe}$, e elevaram os teores de $\mathrm{P}, \mathrm{K}$ e $\mathrm{Mg}$.
\end{abstract}

PALAVRAS-CHAVE: Cerrado; Fertilidade; Solos.

\section{INFLUENCE OF CALCARY DOSAGES ON A DISTROPHIC RED-YELLOW LATOSOLO IN THE SOUTH OF TOCANTINS, BRAZIL ABSTRACT}

Most of the Brazilian soils, in a special way those who are experiencing the expansion of agriculture, such as soil in areas of Cerrado, present characteristics of acidity, toxicity of $\mathrm{Al}$ and low levels of $\mathrm{Ca}$ and $\mathrm{Mg}$. In particular, Tocantinense of soils, have indicated problems in relation to the low fertility, requiring applications of calcareous and fertilizer for agricultural use. They have lower $\mathrm{pH}$ levels than 5.5 with high concentrations of $\mathrm{Al}$ and $\mathrm{Fe}$, and disabled the $\mathrm{P}, \mathrm{K}, \mathrm{Ca}$ and $\mathrm{Mg}$. The objective of the study is the relationship of the effects of liming on soil fertility in different dosage, to correct the $\mathrm{pH}$ and $\mathrm{Al}$ toxicity level. The experiment was conducted in a Red-Yellow Dystrophic Latosol, the Federal 
University of Tocantins campus of Gurupi. The initial doses of Calcium Carbonate PA were: $0.0 ; 1.5 ; 3.0 ; 4.5$ and 6.0 ton / ha ${ }^{-1}$. Every 10 days the evaluations were made in the $\mathrm{pH}$ level in water laboratory. It was found that application of calcium carbonate favored raising the $\mathrm{pH}$, decreasing the levels of $\mathrm{Al}$ and $\mathrm{Fe}$, and raised the levels of $\mathrm{P}, \mathrm{K}$ and $\mathrm{Mg}$.

KEYWORDS: Cerrado; Fertility; Soils.

\section{INTRODUÇÃo}

Os solos sob vegetação de Cerrado são extremamente variados em suas características físicas, químicas e biológicas. Victória et al (2016) retrataram a expansão da fronteira agrícola no Brasil, mostrando que o Brasil se tornou um dos líderes mundiais no agronegócio, e isso foi plausível por causa da disponibilidade dos recursos hídricos, clima, condições de solo e principalmente desenvolvimento de pesquisas, contribuindo para a produção de uma nova fronteira agrícola em áreas do Cerrado, como a região denominada de Matopiba - Maranhão, Tocantins, Piauí e Bahia.

Viola et al. (2014) retratam em seus estudos que o Estado do Tocantins encontra-se em uma zona de transição geográfica entre o Cerrado e a Floresta Amazônica, onde há variações de características físicas de evento de precipitação por região, ocorrendo maior valores de precipitações nas mediações do Parque Estadual do Cantão.

Os solos ácidos tropicais e subtropicais que apresentam deficiência de bases trocáveis $(\mathrm{Ca}, \mathrm{Mg}, \mathrm{K})$, possui níveis de $\mathrm{Al}$ altos, não sendo favoráveis para desenvolvimento de culturas comerciais, mas pode haver complexidade dos elementos ânions orgânicos.

Soares et al. (2015) afirmam que, em solos tropicais as características físicas e químicas do solo nas pesquisas ainda são escassas, sendo necessário ter mais pesquisas em relação a estrutura do solo, seja química, física e biológica, principalmente em solos de derivados de calcário, rocha cujos teores, ajudando na elevação do $\mathrm{pH}$, e entre outros minerais

Os atributos químicos apresentam variações nas propriedades físicas do solo, por isso, o manejo do solo para as práticas agrícolas precisa ser executado com avaliação da intensidade da formação do solo. Neste sentindo, os autores descritos acima retratam sobre a correção da acidez do solo, através da aplicação de Carbonato de Cálcio - $\mathrm{CaCO}_{3}$, confirmando a eficácia na elevação dos teores de $\mathrm{pH}$, favorecendo a disponibilidade de nutrientes na solução do solo.

Nesse sentindo, a correção de calagem depende fundamentalmente de três fatores: da dosagem adequada, das características do corretivo utilizado e da aplicação correta, promovendo a elevação do pH e redução dos teores de alumínio trocável, além de aumentar os teores de cálcio e magnésio e a capacidade de troca de cátions do solo proporcionando um incremento de produção para as culturas.

Devido a grande importância da correção da acidez do solo, objetivou-se com o presente trabalho diferentes doses de calagem em um Latossolo VermelhoAmarelo Distrófico, sob o pH do solo e sua relação com os níveis de toxidez e fertilidade do solo.

\section{MATERIAL E MÉTODOS}

O experimento foi instalado na Fazenda Experimental da Universidade Federal do Tocantins - UFT, em casa de vegetação no Campus Gurupi, a 1144'42 
de latitude Sul, $49^{\circ} 03^{\prime} 04$ de longitude Oeste e altitude de 276 metros. O clima da região é classificado por Tornthwaite, como tropical úmido com pequena deficiência hídrica - B1wA'a', ocorrendo precipitação pluvial média anual entre 1300 a 1500mm, concentrada nos meses de novembro a maio, com temperatura média anual de 27 ${ }^{\circ} \mathrm{C}$ (SEPLAN, 2012). O solo foi classificado, de acordo com SiBCS (Embrapa, 2013), como um Latossolo Vermelho-Amarelo Distrófico.

As amostras do solo foram coletadas na própria área da instituição, sob vegetação de pastagem, sendo retirado na camada de $0-20 \mathrm{~cm}$ de profundidade, em uma quantidade apropriada para a condução do experimento. As amostras foram secas ao ar, destorroada, passada em peneira de $2 \mathrm{~mm}$ e homogeneizada (TFSA Terra Fina Seca ao Ar). O experimento foi conduzido no período de 05 de maio a 03 de julho de 2018.

Dessa forma, o delineamento experimental foi inteiramente casualizado, dividido em 30 amostras de $5 \mathrm{dm}^{3}$ condicionado em sacos plásticos com adicionamento de $\mathrm{CaCO}_{3}$, sendo cinco tratamentos e seis repetições de aplicações equivalentes à 0,$0 ; 1,5 ; 3,0 ; 4,5 ;$ e 6,0 ton ha $^{-1}$, não ocorrendo avaliação de qualquer cultura posterior nos tratamentos e repetições. Os dados foram submetidos a análise de variância (teste F) a $5 \%$ de probabilidade e quando significativo, realizou-se a regressão, plotando os gráficos com o auxílio do software Statistica, versão 7.0

O solo utilizado no experimento foi mantido a $70 \%$ da capacidade de campo, onde a cada três dias, cada embalagem com amostra foi aberta para troca gasosa e reposição da água até $70 \%$ da capacidade de campo. A cada 10 dias foram retiradas 30 gramas de cada amostra para a análise de $\mathrm{pH}$ em laboratório. No final do experimento as amostras foram submetidas à análise em laboratório de solos da própria instituição objetivando a verificação das alterações dos teores de $\mathrm{Ca}+\mathrm{Mg}$, $\mathrm{Ca}, \mathrm{Al}, \mathrm{H}+\mathrm{Al}, \mathrm{K}$ e P.

\section{RESULTADOS E DISCUSSÕES}

A figura 1 apresenta as curvas e equações de regressão e, seus valores médios de $\mathrm{pH}$ do solo submetido as doses crescente nos experimentos com $\mathrm{CaCO}_{3}$, em quatro tipos de comportamentos de dosagem.

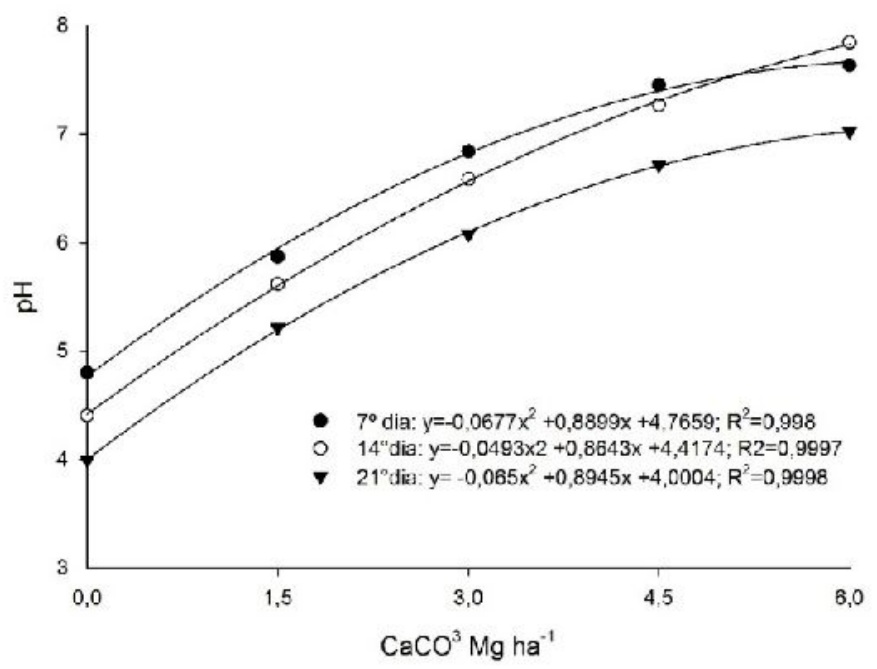

FIGURA 1 - Curvas de calibração do pH do solo Latossolo Vermelho Amarelo, submetido a doses crescentes de $\mathrm{CaCO}_{3}$ 
Portanto, verifica-se que na primeira dosagem houve o efeito da alteração do $\mathrm{pH}$ e a quantidade de dose influenciou no comportamento da alteração do $\mathrm{pH}$. Notase a movimentação física das partículas na primeira dosagem $\mathrm{CaCO}_{3}$ em sua dissolução no solo, chegando no valor médio de $\mathrm{pH}$, as maiorias das culturas necessitam. Entretanto, o aumento da dosagem de $\mathrm{CaCO}_{3}$ não possuem alta elevação dos teores de $\mathrm{pH}$ comparado com a primeira dosagem, mostrando instabilidade depois da terceira dosagem com $\mathrm{CaCO}_{3} \cdot \mathrm{A}$ matéria orgânica, composição estrutural química e física dos minerais do solo relacionado com o material de origem pode contribui para a estabilidade do $\mathrm{pH}$. É importante visar que os latossolos tem alta composição de argila, ajudando na estabilidade

Com base nas afirmações anteriores a correção do solo por calagem é a pratica mais utilizada em solos do Cerrado, pois minimiza acidez e aumenta a capacidade de elementos básicos presentes no solo.

É preciso mencionar que a região do Cerrado o manejo do solo e recomendação de correção de calcário e adubos são extremamente importantes para neutralização de Al e aumentar os valores de fertilidade do solo.

Donagemma et al. (2016), relatam que os solos do Cerrado da região Matopiba são solos de formas gerais que enquadram-se nas classes texturais areia e areia franca ou franco arenosa, até a profundidade de $0,75 \mathrm{~m}$ ou mais, e são representados principalmente pelos Neossolos Quartzarênicos e, em parte, por Latossolos e Argissolos, apresentando características morfológicas bastante variadas.

Entre os fatores ambientais do solo, são os ligados à acidez $(\mathrm{pH}$, saturação por bases, acidez potencial e disponibilidade de nutrientes) que mais interferem na produtividade, especialmente nas regiões tropicais. Em condições de acidez, a calagem promove a neutralização do $\mathrm{Al}^{3+,}$ a elevação do $\mathrm{pH}$ e o fornecimento de $\mathrm{Ca}$ e Mg .

Nesse sentindo vale ressaltar que a formação do solo se inicia com o material de origem que está relacionado com o tipo de rocha. Entretanto, o relevo e o clima determinam o tipo de solo formado, as fragmentações físicas e alterações químicas conhecido como processo de intemperismo, e as oscilações de temperatura promove a dilatação dos minerais, alterando a determinação do nível do $\mathrm{pH}$ no solo

A figura 2 apresenta resultados expostos do $\mathrm{Ca}+\mathrm{Mg}$, em que, o aumento da dosagem de $\mathrm{CaCO}_{3}$ apresentou crescimento do alto nível de $\mathrm{Ca}+\mathrm{Mg}$ em sua composição de formação de fertilidade do solo, constituindo fatores para alcançar aumento da produtividade. No entanto, é preciso verificar o quadro de estabilidade da curva de calibração para diagnosticar que é possível que o crescente $\mathrm{CaCO}_{3}$ contém a quantidade suficiente para retenção da planta. 


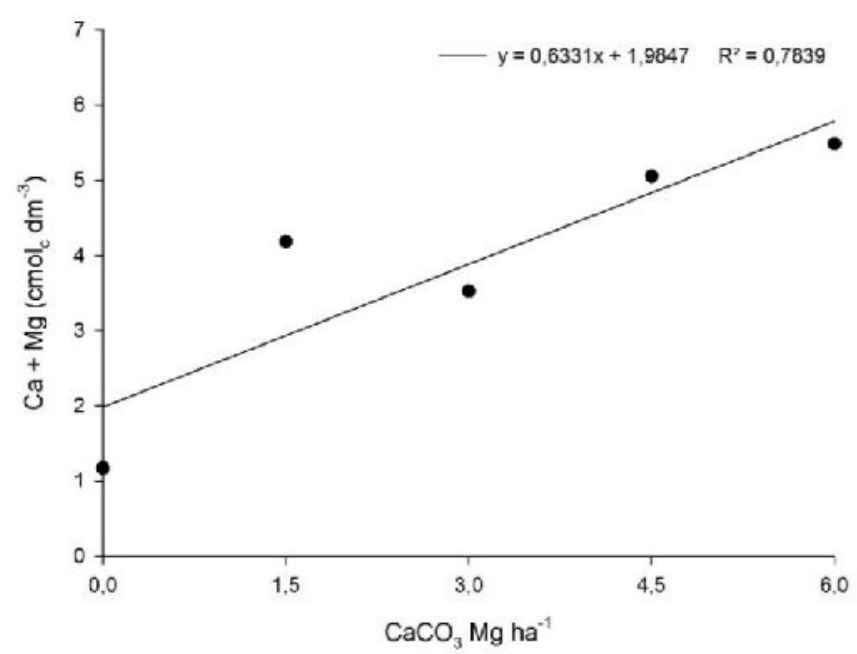

FIGURA 2 - Curvas de calibração do Ca+Mg do solo Latossolo Vermelho Amarelo, submetido a doses crescentes de $\mathrm{CaCO}_{3}$.

A terceira dosagem pode ter diminuído devido a quantidade de cargas do solo, CTC, pH, matéria orgânica. No entanto, as diferenças da quantidade de dosagens mostraram de maneira geral movimentação de Ca e Mg.

Rodrighero et al. (2015) notou que com o aumento dos teores de $\mathrm{CaCO}_{3}$ por $\mathrm{t}$ há $^{-1}$ superficial aumentaram os teores foliares de $\mathrm{Ca}$, e a elevação de $\mathrm{Mg}$ em um Latossolo Vermelho Distrófico, e também no Neossolo Litólico Húmico, causado pela redução da acidez devido a correção. Vale destacar, que o calcário é mais utilizado na agricultura de forma geral, pois é um produto de ocorrência natural, com grande abundância e boa distribuição geográfica e possuem baixa solubilidade em água, e a sua reação dependente do contato e da umidade na superfície.

Farias et al. (2016), afirmam que os solos do Cerrado brasileiro exibem baixa disponibilidade nutricional, elevada acidez e alta concentração de alumínio, podendo inibir e dificultar a absorção de diversos nutrientes, afetando na adsorção/fixação de fósforo $(P)$, como teor de matéria orgânica e presença de ânions, ocorrendo aumento nos teores positivamente de $\mathrm{Ca}, \mathrm{Mg}$ e $\mathrm{P}$.

Atualmente dispõe-se de diversos tipos de corretivos de acidez com características e efeitos diferentes; é necessário conhecê-los para se proceder à escolha do produto mais conveniente a cada situação agrícola. Levando em conta os tratamentos de $\mathrm{CaCO}_{3}$ em seis níveis de amostras com diferentes tipos de dosagem $\left(0 ; 1,5 ; 3,0 ; 4,5\right.$ e 6,0 t há $\left.^{-1}\right)$ retratado na figura 3 , observou-se que o tratamento a primeira dosagem favoreceu a elevação do $\mathrm{Mg}$, no decorrer do aumento da dosagem ouve diminuição da quantidade de eficiência de teor de $\mathrm{Mg}$. Tal comportamento era esperado em função das quantidades crescentes do $\mathrm{pH}$, favorece elevação de $\mathrm{Mg}$. A Elevação de $\left(\mathrm{CaCO}_{3}\right)$ influência na movimentação da disponibilidade de $\mathrm{Mg}$. 


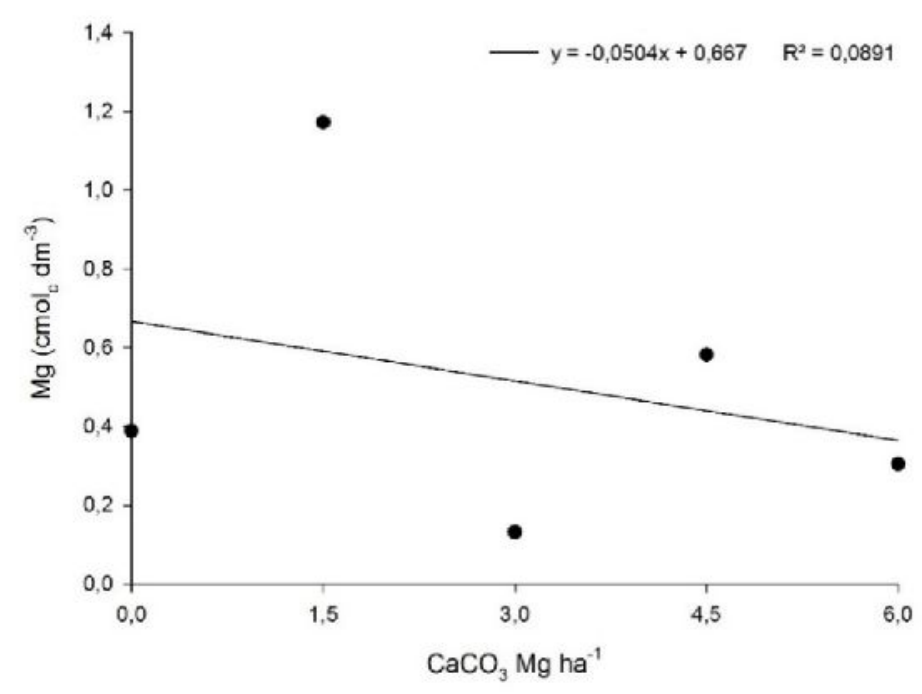

FIGURA 3 - Curvas de calibração do Mg do solo Latossolo Vermelho Amarelo, submetido a doses crescentes de $\mathrm{CaCO}_{3}$

Vale ressaltar também, que o movimento do $\mathrm{Mg}$ com base nas dosagens crescentes de $\mathrm{CaCO}_{3}$ pode ser explicado pela formação de complexos orgânicos hidrossolúveis de cada tipo de solo, promovendo efeito crescente ou decrescente no decorrer do tempo. Desse modo, os sistemas de uso e manejo de uma área têm grande influência sobre os atributos físicos de qualidade do solo, especialmente nas camadas mais superficiais, onde a compressão mecânica parece ser mais atuante.

Considerando a curva de calibração do $\mathrm{H}+\mathrm{Al}$ por aumento de dosagem, na figura 4, observou-se diminuição do $\mathrm{H}+\mathrm{Al}$ considerado satisfatório nas dosagens 1,5 e $30 \mathrm{t}_{\text {há }}{ }^{-1}$, já nas doses 4,5 e 6,0 t há-1 o quadro ficou estável.

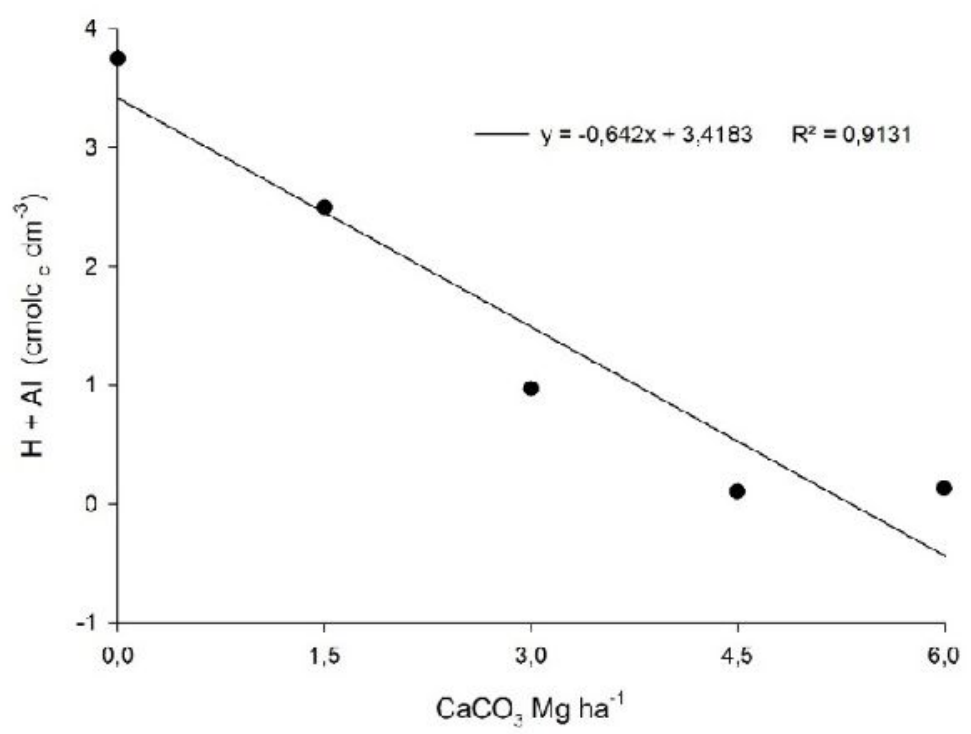

FIGURA 4 - Curvas de calibração do $\mathrm{H}+\mathrm{Al}$ em solo Latossolo Vermelho Amarelo, submetido a doses crescentes de $\mathrm{CaCO}_{3}$ 
As doses crescentes de $\mathrm{CaCO}_{3}$ em relação as doses aplicadas, estão associados aos decrescentes valores de $\mathrm{H}+\mathrm{Al}$, então pode-se afirmar que existem uma relação entre a quantidade de elevação dos macronutrientes a partir do momento que acontece a neutralização de $\mathrm{H}+\mathrm{Al}$ na primeira dosagem de $\mathrm{CaCO}_{3}$.

Al e o H trocáveis são os principais componentes da acidez do solo que limitam o rendimento das culturas. Por ter alta relação com o pH, este é utilizado para recomendação de calagem do solo (NICOLODI et al.,2008). Além disso, os solos podem ter sua acidez aumentada por cultivos e adubações. Em ambos os casos, a acidificação se inicia, ou se acentua, devido à remoção de bases da superfície dos colóides do solo. Nota- se que as características químicas do solo na área da própria instituição podem sofrer algumas alterações, que foram provocados pela ação da natureza antrópica ao longo do tempo.

Natale et al., (2012) retratam que a acidez do solo é um dos fatores que mais interferem na produtividade agrícola, em especial nas regiões tropicais, pois podem ser ácidos, devido à própria pobreza em bases do material de origem, ou aos processos de formações que favorecem a remoção ou lavagem de elementos básicos como $\mathrm{K}, \mathrm{Ca}, \mathrm{Mg}$, $\mathrm{Na}$ e outros.

Além disso, os solos podem ter sua acidez aumentada por cultivos e adubações. Em ambos os casos, a acidificação se inicia, ou se acentua, devido à remoção de bases da superfície dos colóides do solo. Essa formação geológica do ambiente insere-se na transição entre a planície da bacia do rio Araguaia e a planalto do rio Tocantins, apresentando característica distinta de solo em diferente localidade devido aos fatores da formação do solo conforme Aquino et al., (2008).

A necessidade de conhecer os resultados das análises de solos tem como princípio de saber as características, favorecendo a soma de bases, CTC's efetiva (t) e potencial $(\mathrm{T})$, saturação por bases $(\mathrm{V} \%)$, saturação por alumínio $(\mathrm{m} \%)$, percentagem de saturações de $\mathrm{Ca}$, de $\mathrm{Mg}$ e de $\mathrm{K}$, e relação $\mathrm{Ca} / \mathrm{Mg}$.

Em relação ao teor inicial de fósforo no solo (testemunha) houve aumento crescente nos valores no primeiro tratamento, no decorrer do aumento da dosagem ocorreu redução desse nutriente (figura 5).

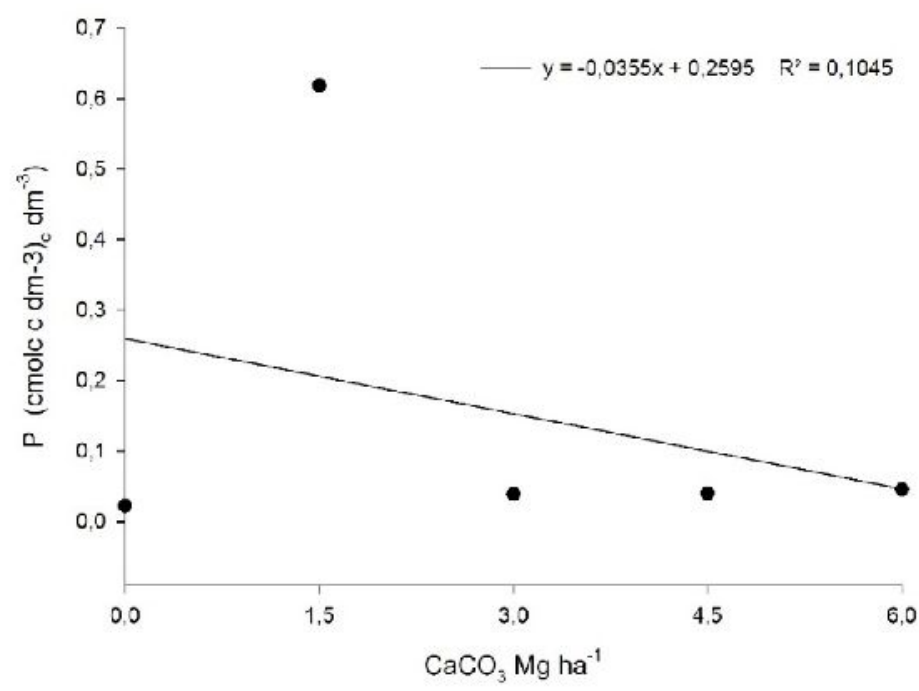

FIGURA 5 - Curva de calibração do P, em solo Latossolo Vermelho Amarelo, submetido a doses crescentes de $\mathrm{CaCO}_{3}$ 
A Figura 5 é a resposta da quantidade de doses crescentes. Essa sorção de $\mathrm{P}$ depende do $\mathrm{pH}$ do solo, verifica-se que a acidez afeta a disponibilidade de fósforo. Entretanto, a incorporação de calcário no Latossolo Vermelho Amarelo não houve muita alteração. Por outro lado, os outros nutrientes ocorreram em níveis crescentes. O efeito da correção nem sempre é crescente para todos os macronutrientes.

Simon (2016) no seu trabalho em relação a queima de resíduos do solo sob atributos químicos de um Latossolo Vermelho Distrófico do cerrado define que o fogo é um instrumento de manejo em diversos tipos de ecossistemas, e não houve interação entre os tipos de manejo de solo para os nutrientes $\mathrm{K}, \mathrm{Al}, \mathrm{Ca}, \mathrm{Mg}$, para as relações $\mathrm{Ca}+\mathrm{Mg}, \mathrm{H}+\mathrm{Al}$, matéria orgânica $(\mathrm{MO})$, carbono orgânico $(\mathrm{CO})$ e saturação por $\mathrm{Al}(\mathrm{m} \%)$ em função da queima, houve diferença significativa, entre as camadas do solo para os teores de MO, K, Ca, Mg, Al, $\mathrm{Ca}+\mathrm{Mg}$ e CO (Tukey, $5 \%$ ).

De acordo com Guimarães (2015), a calagem é prática obrigatória na plantação de eucalipto, apesar do eucalipto ser tolerante à acidez e ao alumínio. $\mathrm{O}$ calcário é necessário devido a exigência em cálcio e magnésio da cultura. Para o autor recomenda-se aplicação de calcário dolomítico, nas doses de 1,0 a 2,5 t/há, de acordo com resultados da análise química do solo.

Nota-se na figura 6 que a aplicação das doses crescentes de $\mathrm{CaCO}_{3}$ o estado do $\mathrm{K}$ foi alterado no decorrer do aumento das dosagens. Observou-se que depois da segunda dosagem os teores de K sofreram alterações de aumento ao longo do período de tempo de análise.

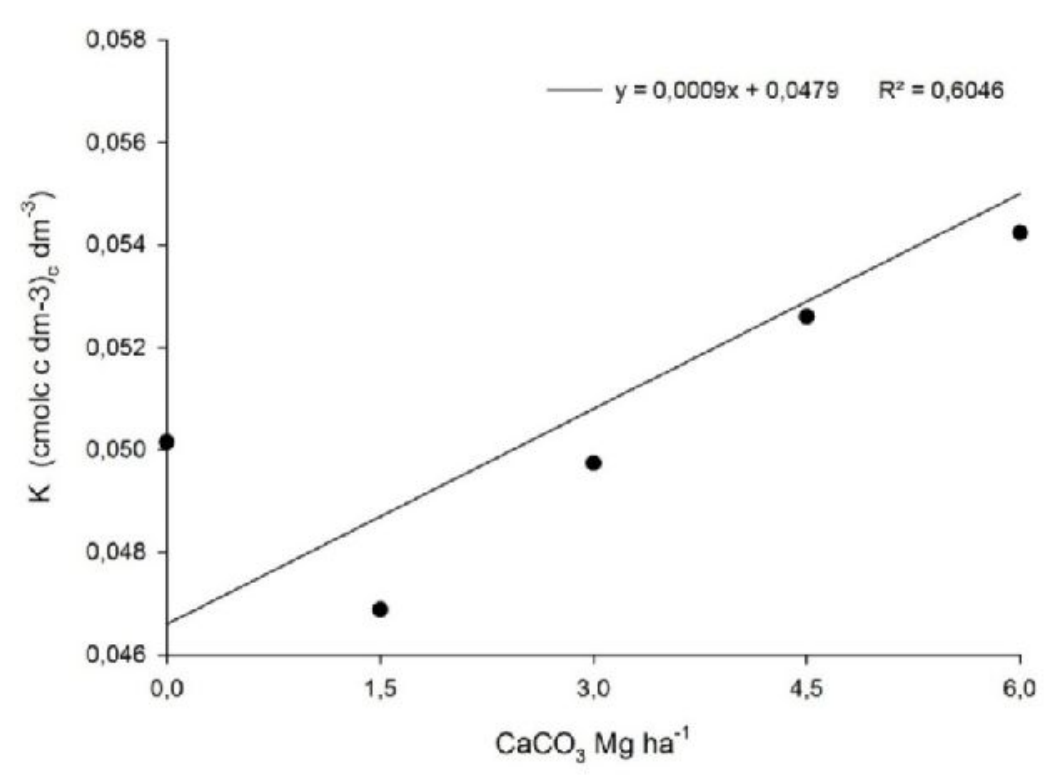

FIGURA 6 - Curva de calibração do K, em solo Latossolo Vermelho Amarelo, submetido a doses crescentes de $\mathrm{CaCO}_{3}$ 
Dessa forma, o uso crescente de $\mathrm{CaCO}_{3}$, pode apresentar melhores resultados de produção. O calcário pode elevar os teores de $\mathrm{Ca}, \mathrm{Mg}$ e $\mathrm{K}$ do solo e estimular o aumento no crescimento da parte aérea das plantas SANTIN, et al (2013).

\section{CONCLUSÕES}

A correção da acidez do solo através da aplicação de Carbonato de Cálcio $\mathrm{CaCO}_{3}$ no Latossolo Vermelho Distrófico, mostrou eficácia na elevação dos teores de $\mathrm{pH}, \mathrm{Ca}+\mathrm{Mg}, \mathrm{Mg}$ e $\mathrm{K}$, havendo diferença significativa entre os teores de tamanho de dosagem. Houve diminuição dos teores de $\mathrm{H}+\mathrm{Al}$ e $\mathrm{P}$ para todas as doses, pois a medida que aumentou as doses de $\mathrm{CaCO} 3$, diminuiu os teores de $\mathrm{H}+\mathrm{Al}$ e $\mathrm{P}$.

Diante dos dados, verifica-se que a aplicação do carbonato de cálcio pode alterar o comportamento químico do solo devido a correção da acidez do solo.

\section{AGRADECIMENTOS}

Os autores agradecem a todos os funcionários do laboratório de solo da Universidade Federal do Tocantins-Campus - Gurupi-TO por auxiliar nos testes das amostras de solos.

\section{REFERÊNCIAS}

AQUINO, S; LATRUBESSE. E. M; FILHO. E. E. S. Relações entre o regime hidrológico e os ecossistemas aquáticos da planície aluvial do rio Araguaia. Acta Scientiarum. Biological Sciences, v. 30, 2008. Maringá, v. 30, n. 4, p. 361-369, 2008. Disponível em:< http://www.redalyc.org/articulo.oa?id=187116040004>. doi: 10.4025/actascibiolsci.v30i4.5866

DONAGEMMA, G. K., FREITAS, P. L. D., BALIEIRO, F. D. C., FONTANA, A., SPERA, S. T., LUMBRERAS, J. F., ... \& MACEDO, M. C. M. Characterization, agricultural potential, and perspectives for the management of light soils in Brazil. Pesquisa Agropecuária Brasileira, v. 51, n. 9, p. 1003-1020, 2016. Disponível em:<http://www.scielo.br/pdf/pab/v51n9/pt_0100-204X-pab-51-09-1003.pdf>. doi: http://dx.doi.org/10.1590/s0100-204x2016000900001

EMPRESA BRASILEIRA DE PESQUISA AGROPECUÁRIA - EMBRAPA. Centro Nacional de Pesquisa de Solos. Manual de métodos de análise de solos. 3. ed. Rio de Janeiro: EMBRAPA, 2013.

FARIAS, S. C. C.; SILVA JÚNIOR, M. L.; RUIVO, M. L. P.; RODRIGUES, P. G.; MELO, V. S.; COSTA, A. R.; SOUZA JÚNIOR, J. C. Phosphorus Forms in Ultisol Submitted to Burning and Trituration of Vegetation in Eastern Amazon. Revista Brasileira de Ciência do Solo, 2016. Disponível em:< https://sistemas.ifgoiano.edu.br/sgcursos/uploads/anexos_5/2018-01-08-10-3329Andr\%C3\%A9ia\%20Mendes\%20da\%20Costa.pdf>. doi: http://dx.doi.org/10.1590/18069657rbcs20150198.

GUIMARÃES, C. D. C., FLORIANO, E. P., \& VIEIRA, F. C. B. Chemical constraints to initial growth of Eucalyptus saligna in sandy soils of Pampa Gaúcho: a case study. Ciência Rural, v. 45, n. 7, p. 1183-1190, 2015. Disponível em:< 
http://www.scielo.br/pdf/cr/v45n7/0103-8478-cr-cr20120533.pdf>. doi:10.1590/01038478 cr20120533.

NATALE, W., ROZANE, D. E., PARENT, L. E., PARENT, S. É. Soil acidity and liming in tropical fruit orchards. Revista Brasileira de Fruticultura, v. 34, n. 4, p. 12941306, 2012. Disponível em:< https://www.intechopen.com/books/soil-fertility/soilacidity-and-liming-in-tropical-fruit-orchards>. doi: http://dx.doi.org/10.5772/53345.

NICOLODI, M., ANGHINONI, I., \& GIANELLO, C. Relações entre os tipos e indicadores de acidez do solo em lavouras no sistema plantio direto na região do Planalto do Rio Grande do Sul. Revista Brasileira de Ciência do Solo, v. 32, n. 3, p. 1217-1226, 2008. Disponível em:<http://www.scielo.br/pdf/rbcs/v32n1/23.pdf>.

RODRIGHERO, M. B., BARTH, G., \& CAIRES, E. F. Surface application of lime with different magnesium contents and particle sizes under a no-till system. Revista Brasileira de Ciência do Solo, v. 39, n. 6, p. 1723-1736, 2015. Disponível em:< http://www.scielo.br/pdf/rbcs/v39n6/0100-0683-rbcs-39-6-1723.pdf>. doi: http://dx.doi.org/10.1590/01000683rbcs20150036.

SANTIN, D., BENEDETTI, E. L., KASEKER, J. F., BASTOS, M. C., REISSMANN, C. B., WENDLING, I., BARROS, N. F. D. Nutrição e crescimento da erva-mate submetida à calagem. Ciência Florestal, v. 23, n. 1, p. 55-66, 2013. Disponível em:< https://ainfo.cnptia.embrapa.br/digital/bitstream/item/100248/1/2013-API-

NutricaoCrescimento.pdf>.

SEPLAN - SECRETARIA DO PLANEJAMENTO E MEIO AMBIENTE. Diretoria de zoneamento ecológico-econômico. Atlas do Tocantins: subsídios ao planejamento da gestão territorial, $2012 . \quad$ Disponível em:<http://web.seplan.to.gov.br/Arquivos/download/ZEE/TO_AtlasTocantins2012/Atl as_do_Tocantins_2012.pdf >.

SIMON, C. A., RONQUI, M. B., ROQUE, C. G., DESENSO, P. A. Z., DE SOUZA, M. A. V., KÜHN, I. E., CAMOLESE. I, E; SIMON, C. P. Efeitos da queima de resíduos do solo sob atributos químicos de um Latossolo Vermelho Distróflico do cerrado. Nativa, v. 4, n. 4, p. 217-221, 2016. Disponívem em:< http://periodicoscientificos.ufmt.br/ojs/index.php/nativa/article/view/3266/2821 > doi: http://dx.doi.org/10.14583/2318-7670.v04n04a06

SIQUEIRA, P. R. E., \& SIQUEIRA, P. R. B. Evolução dos níveis de fertilidade do solo em lavouras de soja interpretados com duas recomendações oficiais. Revista Científica Rural, v. 20, n. 1, p. p. 92-107, $2018 . \quad$ Disponível em:<file://C:/Users/s/Downloads/262-1042-1-PB.pdf>.

SOARES, L. C., LINHARES, L. A., EGREJA FILHO, F. B., WINDMOLLER, C. C., \& YOSHIDA, M. I. Mercúrio em solos da região sudeste do Brasil sem influência antropogênica e sua correlação com as características químicas e físicas. 2015. Revista Brasileira de Ciências do Solo, vol.39, n.3, pp.903-914, 2015. Disponível em:<http://www.redalyc.org/pdf/1802/180240404028.pdf>. doi: http://dx.doi.org/10.1590/01000683rbcs20140411. 
SPERA, S. T., ESCOSTEGUY, P. A. V., DOS SANTOS, H. P., \& KLEIN, V. A. A solução do solo de um latossolo vermelho distrófico submetido a três tipos de manejo de solo e de culturas. Embrapa Agrossilvipastoril-Artigo em periódico indexado (ALICE), $2014 . \quad$ Disponível em:< https://www.researchgate.net/publication/266741185/download > Acesso em 4 set. 2018.

VICTÓRIA, D. D. C., CONTINI, E., BAYMA-SILVA, G., SPINELLI-ARAUJO, L., \& GOMES, D. Matopiba em crescimento agrícola. Revista Política Agrícola. Ano XXV - № 4 - $\quad$ Out./Nov./Dez. 2016. Disponível em:<https://ainfo.cnptia.embrapa.br/digital/bitstream/item/160156/1/Matopiba-emcrescimento-agricola.pdf>.

VIOLA, M. R., AVANZI, J. C., MELLO, C. R. D., LIMA, S. D. O., \& ALVES, M. V. G. Distribution and erosive potential of rainfall in the state of Tocantins, Brazil. Pesquisa Agropecuária Brasileira, v. 49, n. 2, p. 125-135, 2014. Disponível em:<http://www.scielo.br/pdf/pab/v49n2/0100-204X-pab-49-02-00125.pdf> doi: http://dx.doi.org/10.1590/S0100-204X2014000200007. 